\title{
ASIRAS airborne radar resolves internal annual layers in the dry-snow zone of Greenland
}

\author{
R. L. Hawley, ${ }^{1}$ E. M. Morris, ${ }^{2,3}$ R. Cullen, ${ }^{4}$ U. Nixdorf, ${ }^{5}$ A. P. Shepherd, ${ }^{1}$ \\ and D. J. Wingham ${ }^{6}$ \\ Received 6 November 2005; revised 21 December 2005; accepted 4 January 2006; published 21 February 2006.
}

[1] We present data from the European Space Agency's Airborne SAR/Interferometric Radar Altimeter System (ASIRAS), flown during the CryoVex 2004 field calibration/validation campaign, and new, high-resolution depth profiles of snow density measured in the field by neutron scattering. We combine these data to calculate the depth of internal reflecting horizons in the ASIRAS data. The high resolution density data allow us to identify annual layers in the snow density profile, and correlate their peaks with the reflecting horizons. We use the thickness of the annual layers combined with the density profile to determine the spatial and temporal pattern of snow accumulation along the radar track, for a period of 6 years from 1995-2002. Our mean-annual accumulation rate is $0.47 \pm 0.09 \mathrm{ma}^{-1}$ water equivalent, in agreement with the value determined from a core taken in this location in 1992. Similarly, our interannual variability shows the same trends as recent model estimates over the entire ice sheet. Because ASIRAS was designed to mimic as closely as possible the characteristics of the SAR/Interferometric Radar Altimeter (SIRAL), the principal payload of CryoSat, the detection of internal layering with ASIRAS illuminates the possibility of detecting internal layers with a space-borne radar, and thus the possible application of this technique to the dry-snow zones of Antarctica, Greenland, and smaller ice bodies. Citation: Hawley, R. L., E. M. Morris, R. Cullen, U. Nixdorf, A. P. Shepherd, and D. J. Wingham (2006), ASIRAS airborne radar resolves internal annual layers in the dry-snow zone of Greenland, Geophys. Res. Lett., 33, L04502, doi:10.1029/ 2005 GL025147.

\section{Introduction}

[2] Knowledge of the state of Earth's large ice sheets in Antarctica and Greenland is of critical importance in assessing the response of the Earth to changes in climate. The Greenland ice sheet alone contains enough water to raise global sea level by approximately 5 meters UK

${ }^{1}$ Scott Polar Research Institute, University of Cambridge, Cambridge,

${ }^{2}$ British Antarctic Survey, Cambridge, UK.

${ }^{3}$ Now at Scott Polar Research Institute, University of Cambridge, Cambridge, UK.

${ }^{4}$ European Space Research and Technology Center, European Space Agency, Noordwijk, Netherlands.

${ }^{5}$ Alfred Wegener Institute for Polar and Marine Research, Bremerhaven, Germany.

${ }^{6}$ Centre for Polar Observation and Modelling, University College London, London, UK.

Copyright 2006 by the American Geophysical Union. 0094-8276/06/2005GL025147\$05.00
[Intergovernmental Panel on Climate Change, 2001], were it all to melt. In quantifying mass balance, the mass input to the ice sheet, or accumulation, is measured, typically using stakes or shallow ice cores [e.g., Fischer et al., 1995; Box et $a l ., 2004]$. Since stakes and shallow cores provide sparsely spaced temporal records of accumulation, recent studies have included internal layers detected with Radio Echo Sounding (RES), and inferred to be isochrones, to provide spatially continuous accumulation estimates [Kohler et al., 1997; Fahnestock et al., 2001; Kanagaratnam et al., 2004; Vaughan et al., 2004].

[3] Here, we use data from the European Space Agency's Airborne SAR/Interferometric Radar Altimeter System (ASIRAS), a prototype of the CryoSat altimeter. We identify internal reflecting horizons in the upper 10 meters of the dry-snow zone of Greenland. We combine the radar data with field measurements of snow density to identify the internal reflectors in the radar data as annual layers. This identification of annual layers allows us to determine spatial and temporal patterns of snow accumulation between 1995 and 2002 along a traverse of the Greenland Ice Sheet.

\section{Location}

[4] The radar data were collected along the line of the International Glaciological Greenland-Expedition (EGIG) traverse. The flight line started at $\mathrm{N} 70.46^{\circ}$, W $043.65^{\circ}$ and ended at $\mathrm{N} 70.58^{\circ}$, W $042.88^{\circ}$. Snow density data were collected in a borehole at the point designated as $\mathrm{T} 21$, located at $\mathrm{N} 70.54^{\circ}$, W $043.03^{\circ}$.

\section{Data and Methods}

\subsection{ASIRAS Radar Data}

[5] The Airborne SAR/Interferometric Radar Altimeter System (ASIRAS) [Lentz et al., 2002] is the first of ESA's new generation of pulse-width limited radar altimeters and was originally designed to demonstrate the concept of a SAR-interferometric altimeter system in support of ESA's CryoSat mission. The radar is very similar to the delayDoppler Phase-monopulse system described by Raney [1998] and Raney and Leuschen [2004], and is essentially the same as a $\mathrm{Ku}$ band altimeter but with a high pulse repetition frequency such that it is phase sensitive and pulse-coherent. Dual receive antennae oriented adjacent to one another across-track form a single-pass interferometer. The carrier frequency of the radar is $13.5 \mathrm{GHz}$ and the bandwidth is $1 \mathrm{GHz}$.

[6] To achieve high sampling resolution of about 4.5 metres in the along-track direction (with the aircraft $\approx 1 \mathrm{~km}$ above the target surface), the system uses the 


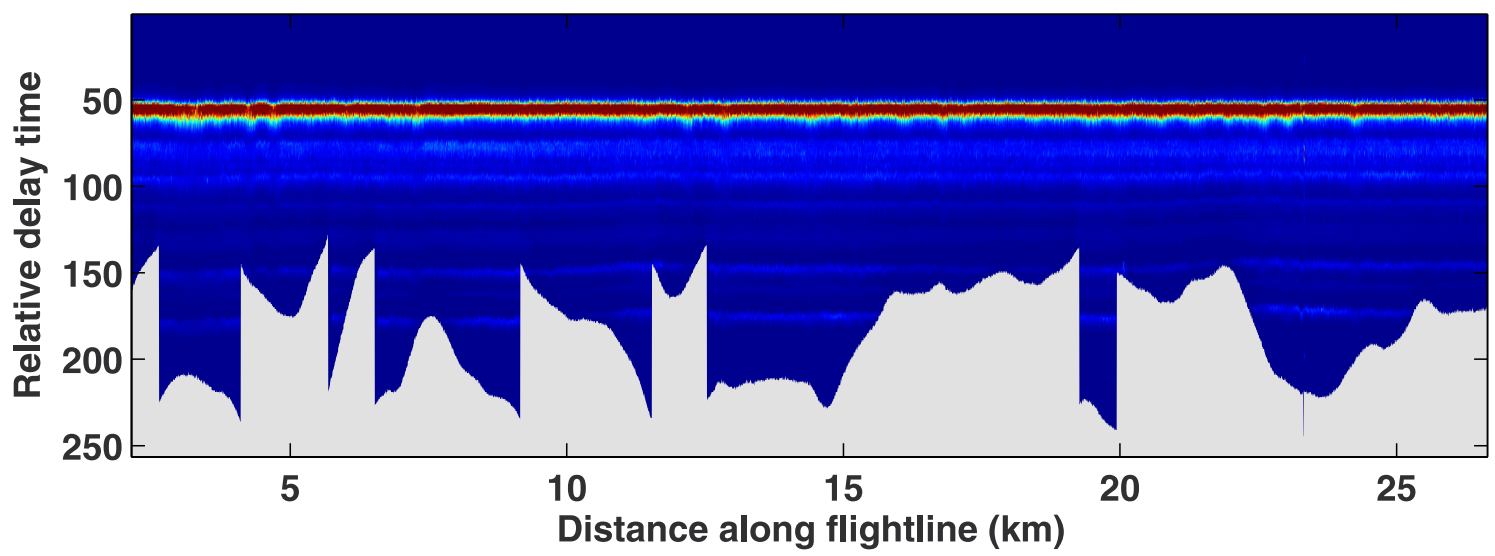

Figure 1. The ASIRAS Level $1 \mathrm{~b}$ power echoes. The power waveforms have all been shifted to position the surface return at the same relative delay time, thus the surface appears flat. The surface return is clearly apparent, as are several of the internal layers used in this study. The grey shaded region at the bottom indicates that there are no data; ASIRAS is designed to "listen" only for a short time before and after the expected surface return, and this time-window varies.

delay-doppler concept [Raney, 1998] to form 'beams'. The echoes illuminated by these beams are corrected for the effect of slant range as the instrument passes over and samples any given surface location (the 'SAR' component of the radar). Using the difference in phase between the echoes received by the two antennae, the across-track location of the point of closest approach can be pinpointed (the 'interferometric' component of the radar). In order to reduce fluctuation in echoes due to thermal noise and speckle, averaging of echoes is required. This is known as multi-looking [Wingham et al., 2004]. Aircraft position and attitude are measured with a Differential Global Positioning System (DGPS) and an Inertial Navigation System (INS).

[7] We processed the raw, uncalibrated radar data using the ESA ASIRAS L1b processor version 2.01, in which the delay-doppler slant range compensation is applied and the resulting multi-looked echo waveforms are geo-located using the DGPS and INS information. In this work we consider only the power of the received echo. For each location, the power of the received echo is sampled as a time series in 256 'range bins'. The synthetic aperture processed power echoes are shown in Figure 1. The significant peak from the surface can clearly be seen, as can several other secondary reflectors.

\subsection{Density Profile}

[8] We collected high-resolution ( $1 \mathrm{~cm}$ intervals) density data to a depth of 11.4 meters at the EGIG site T 21 with a new neutron density profiling system containing a fast neutron source and a slow neutron detector [Morris and Cooper, 2003], using a $5 \mathrm{~cm}$ augered hole for access. Fast neutrons are scattered by hydrogen atoms, slowing in the process, so that the number of slow neutrons arriving at the detector is related to the density of the surrounding snow. The resulting depth-density profile reveals annual layering, and can be seen in the left hand panel of Figure 2 .

\subsection{Travel Time-Depth Conversion}

[9] The temporal spacing of the 256 range bins can be related to the properties of the radar system by

$$
T_{t w t}=\frac{T_{u c} F_{s}}{B N_{s}}
$$

where $T_{t w t}$ is the two-way travel time, $T_{u c}=4 \mu \mathrm{s}$ is the uncompressed pulse length, $F_{S}=37.5 \mathrm{MHz}$ is the instrument sampling frequency, $B=1 \mathrm{GHz}$ is the instrument bandwidth, and $N_{s}=256$ is the number of samples.

[10] To determine the depth to a given reflector, we calculated the relative permittivity $\varepsilon_{\text {eff }}$ the snow from the

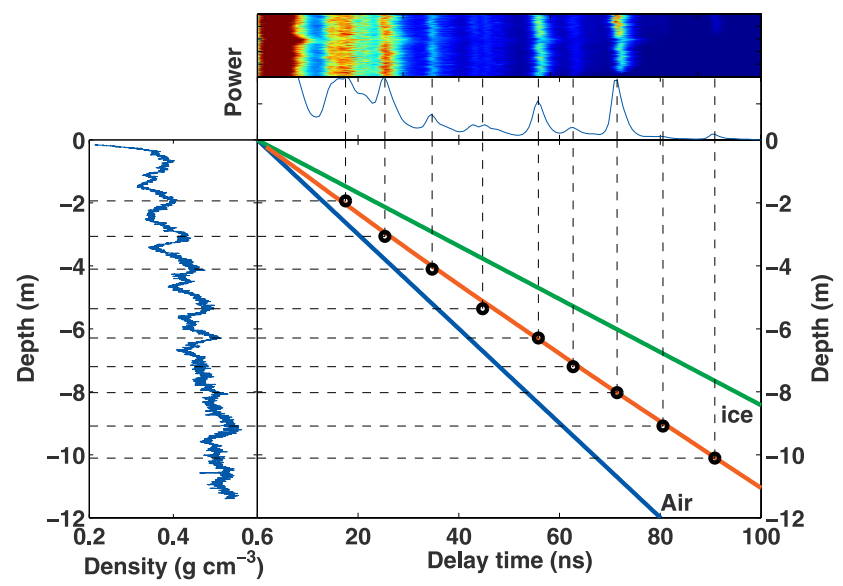

Figure 2. The relationship between ASIRAS radar power return and the snow/firn density profile from the neutronscattering probe. (left) The density profile at site T 21 on the EGIG line. The prominent peaks in density are interpreted as annual winter horizons. (top) The power return in the region of $\mathrm{T} 21$. The power is presented as both a trace showing the mean of 30 adjacent traces, and a color plot showing approximately $1 \mathrm{~km}$ around T 21. (middle) Traveltime versus depth; to compare the radar return to the density profile, we calculate the wave speed in snow using a mixing model [Looyenga, 1965]. The expected depth-travel time curve, calculated with these density data, is shown by the red line, and depth-travel time curves calculated for solid ice and air are plotted as green and blue lines. Lines drawn from peaks in the density profile intersect with lines drawn from peaks in the power return at locations marked by the small circles. These locations fall along the expected depth-travel time curve, indicating that the peaks in the power return are associated with annual high density layers. 


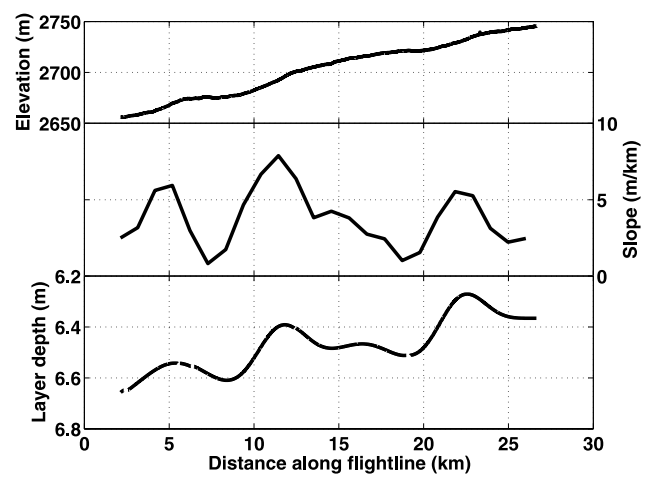

Figure 3. Spatial variability of accumulation along the radar track. (top) Surface elevation as determined by the ASIRAS radar altimeter. (middle) Surface slope. (bottom) Depth to the 5th layer, the deepest continuously traceable layer (a proxy for relative accumulation rate).

relative permittivity of ice $\varepsilon_{\text {ice }}$ using a formulation of the 'mixing' relationship (snow being a mixture of ice and air) of [Looyenga, 1965]:

$$
\varepsilon_{e f f}=\left(1+v\left(\varepsilon_{i c e}^{\frac{1}{3}}-1\right)\right)^{3},
$$

where the volume fraction $v=\frac{\rho}{\rho_{\text {ice }}}$ was calculated from the measured density profile $\rho$ at $\mathrm{T} 21$. From the permittivity we calculated the electromagnetic wave speed and thus a travel-time depth relationship for a given range bin. This relationship is summarized in Figure 2.

\section{Results}

\subsection{Density}

[11] The density profile from site T 21 (Figure 2) shows a distinct pattern of fluctuations between high and low density, superimposed on the gradual trend of densification due to increasing overburden. These fluctuations are characteristic of the classic annual layer cycle commonly used for dating ice cores [e.g., Alley et al., 1997]. Repeat density measurements in spring and autumn show the high density peak to be formed in winter snow. The peaks in density, therefore, represent annual winter horizons.

\subsection{Internal Layers}

[12] Peaks in power arriving after the surface return can arise through 3 principal mechanisms: 1) instrumental artifacts, 2) off-nadir reflecting sources, and 3) internal scattering horizons in the ice. If the secondary reflectors were instrumental artifacts, we would expect them to have certain predictable characteristics; for example they would likely occur at the same delay time in the signal regardless of the location of the surface. The reflectors (see Figure 1) do not show this property, rather they follow the surface contour, with slight deviations. If the reflections were due to some off-nadir feature, it would have to lie parallel to the aircraft track along the whole flight line, to maintain a similar delay-time throughout the profile. The most plausible explanation is that the secondary echoes are internal scattering horizons. For example, the reflectors are upwarped in areas of relatively steep slope, the expected behaviour for accumulation-driven layering since these areas have lower accumulation rates [Black and Budd, 1964; Hamilton, 2004]. In Figure 2, we show the relationship of the internal layers in the power profile to the peaks in density. The depths of the high density winter peaks are correlated with local peaks in radar power return, indicating that the peaks in the power return are annual layers. In most RES studies of internal layering, isochronous layers are identified, but here we identify annual layers. This distinction is important because it allows us to examine more detailed temporal changes in accumulation, in addition to spatial changes.

\section{Discussion}

\subsection{Accumulation Rates}

[13] Identification of annual layers allows us to calculate annual accumulation rates using the geometry of the internal layers and the density profile. To determine the geometry of the internal layers (the depth to each layer measured at each point along the flight path), we used a simple algorithm to locate peaks in power occurring within subsets of the complete waveform. To reduce the effect of noise, we averaged 30 adjacent traces (covering a distance of $\approx 135$ meters) along-track before picking layer locations. For each layer, we measured the thickness and calculated its mass using the mean density (measured at site T 21) over its depth. The mean annual accumulation along the flight line is $0.47 \pm 0.09 \mathrm{ma}^{-1}$, in agreement with the value reported by Fischer et al. [1995] of $0.439 \pm$ $0.088 \mathrm{ma}^{-1}$ for a core drilled at T 21 in 1992. Identification of annual layers in this way gives us the ability to determine both spatial and temporal variations in accumulation rate along the aircraft flight line, qualitatively visible in Figure 1.

\subsubsection{Spatial Variability}

[14] ASIRAS-identified accumulation layers allow us to investigate spatial variability in accumulation along the

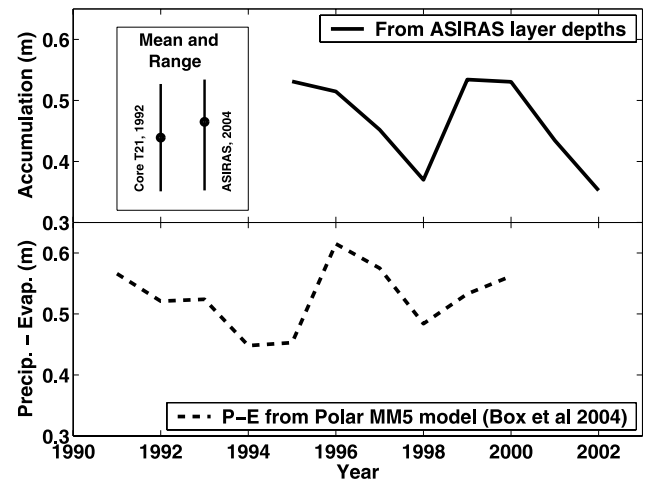

Figure 4. Temporal variability of accumulation. (top) Yearly mean accumulation along the ASIRAS flight line calculated from layer depths and densities. Inset: The mean annual accumulation from ASIRAS layering compared with the mean annual accumulation measured in a core from $\mathrm{T} 21$ taken in 1992 by Fischer et al. [1995]. Note that the vertical bars indicate the excursions from the mean, rather than error estimates. (bottom) Accumulation (precipitation sublimation/evaporation) over all of Greenland as calculated by Box et al. [2004] using the polar MM5 climate model. 
flightline. To quantify the spatial variability, we use the burial depth of the deepest (oldest) continuously-traceable layer (the 5th layer in our survey) as a measure of the 5-year total accumulation, a reasonable proxy if the depth-density profile varies little over the length of the flight line. In Figure 3 we present the spatial variability of this 5 -year accumulation along the flight line. The overall trend is decreasing accumulation with increasing elevation, in agreement with the large-scale pattern in the map of Bales et al. [2001]. Superimposed on this trend is short scale variability, due to variations in local topography. Elsewhere, areas of steeper slope have been observed to have lower accumulation, most likely due to higher katabatic (gravity driven) winds [Black and Budd, 1964; Hamilton, 2004], and a similar pattern is present here.

\subsubsection{Temporal Variability}

[15] Because we can resolve multiple annual layers in the dry snow zone, we can examine the interannual variability in accumulation. The interannual variability of accumulation is of great interest in mass balance studies, and many have measured and modeled it in Greenland [McConnell et al., 2001; Bromwich et al., 2001; Box et al., 2004]. We average the accumulation for a given year over the flight line. This average value can be compared with the results of other studies. In Figure 4 we compare the inter-annual variability of accumulation along our flight line with the variability reported by Box et al. [2004] over the whole of the ice sheet. While it is evident (and to be expected) that the magnitudes of the accumulation rates differ slightly, the changes in the two time series are in phase.

\subsection{Applicability to Space-borne Radar Altimeters}

[16] Since ASIRAS was designed to mimic the operation of SIRAL, the CryoSat altimeter, it is natural to consider whether data from a space-borne radar altimeter could be used to determine accumulation. Although the operating principles of the two instruments are similar, there are several key differences. The range resolution of SIRAL is $\approx 47 \mathrm{~cm}$ in air [Wingham et al., 2006], as opposed to $\approx 8.8 \mathrm{~cm}$ in air for ASIRAS. Although the reduced wave speed in snow/firn improves resolution, it is possible that annual layers in lower accumulation areas would not be resolved. Nevertheless, interference patterns from several layers, as commonly detected by ice-penetrating radars [Harrison, 1973], may be resolved by a space-borne radar like SIRAL. Although these 'multiple layer' reflections will not give us detailed temporal information on accumulation, they should at least reveal spatial patterns in accumulation. Finally, the larger footprint of a space-borne radar altimeter as compared to ASIRAS may mean that across-track surface returns from the larger footprint may overwhelm the relatively small returns from internal layering in the 'tail' of the echo.

\section{Conclusions}

[17] We have imaged continuous internal layers in the dry snow zone of the Greenland ice sheet with ASIRAS. We have shown that these layers coincide with density peaks we have measured in the upper meters of the snow, which we believe to be annual horizons. Identification of internal layers allows us to examine spatial variability in accumu- lation in the area of $\mathrm{T} 21$, which is dominated by topography. The mean annual accumulation calculated using the measured densities and layer depths agrees with mean annual accumulation estimates measured in a core from the same location in 1992 [Fischer et al., 1995]. Resolving annual layers with ASIRAS illuminates the interannual variability in accumulation in the area, which agrees qualitatively with variability predicted by a modeling analysis using the polar MM5 climate model [Box et al., 2004]. While untested, a space-borne instrument like SIRAL may be capable of detecting similar internal layering in the drysnow zones of polar ice sheets, allowing the potential to determine spatial and temporal patterns of accumulation variability over wide areas.

[18] Acknowledgments. This work is supported by the Natural Environmental Research Council, and the European Space Agency. We thank Constanin Mavrocordatos and everyone involved in the development of the ASIRAS instrument at Radar Systematik (RST) and ESA. We thank all team members involved in the CryoVex 2004 campaign, particularly the air crew who flew the radar system, including Tobias Boebel of Optimare and Harald Lenz of RST. We are grateful for field support from Geoff Somers and John Pailthorpe. Figure 2 was inspired by Kohler et al. [1997, Figure 4]. We thank Tom Neumann and two anonymous reviewers for their comments, which improved the manuscript. Finally we thank GRL editor James E. Saiers for his handling of the manuscript.

\section{References}

Alley, R. B., et al. (1997), Visual-stratigraphic dating of the GISP2 ice core: Basis, reproducibility, and application, J. Geophys. Res., 102, 26,36726,382.

Bales, R. C., J. R. Mcconnell, E. Moseley-Thompson, and B. Csatho (2001), Accumulation over the Greenland ice sheet from historical and recent records, J. Geophys. Res., 106, 33,813-33,825.

Black, H. P., and W. Budd (1964), Accumulation in the region of Wilkes, Wilkes Land, Antarctica, J. Glaciol., 5, 3-15.

Box, J. E., D. H. Bromwich, and L. Bai (2004), Greenland ice sheet surface mass balance 1991-2000: Application of Polar MM5 mesoscale model and in situ data, J. Geophys. Res., 109, D16105, doi:10.1029/ 2003JD004451.

Bromwich, D. H., Q. Chen, L. Bai, E. N. Cassano, and Y. Li (2001), Modeled precipitation variability over the Greenland ice sheet, J. Geophys. Res., 106, 33,891-33,908.

Fahnestock, M., W. Abdalati, S. Luo, and S. Gogineni (2001), Internal layer tracing and age-depth-accumulation relationships for the northern Greenland ice sheet, J. Geophys. Res., 106, 33,789-33,797.

Fischer, H., D. Wagenbach, M. Laternser, and W. Haeberli (1995), Glaciometerological and isotopic studies along the EGIG line, central Greenland, J. Glaciol., 41, 515-527.

Hamilton, G. S. (2004), Topographic control of regional accumulation rate variability at South Pole and implications for ice core interpretation, Ann. Glaciol., 39, 214-218.

Harrison, C. H. (1973), Radio echo sounding of horizontal layers in ice, J. Glaciol., 12, 383-397.

Intergovernmental Panel on Climate Change (2001), Climate Change 2001: The Scientific Basis: Contribution of Working Group I to the Third Assessment Report of the Intergovernmental Panel on Climate Change, edited by J. T. Houghton et al., 881 pp., Cambridge Univ. Press, New York.

Kanagaratnam, P., S. P. Gogenini, V. Ramasami, and D. Braaten (2004), A wideband radar for high-resolution mapping of near-surface internal layers in glacial ice, IEEE Trans. Geosci. Remote Sens., 42, 483-490.

Kohler, J., J. Moore, M. Kennett, R. Engeset, and H. Elvehoy (1997), Using ground-penetrating radar to image previous years' summer surfaces for mass-balance measurements, Ann. Glaciol., 24, 355-360.

Lentz, H., H.-M. Braun, M. Younis, C. Fletcher, W. Wiesbeck, and C. Mavrocordatos (2002), Concept and realization of an airborne SAR/ Interferometric Radar Altimeter System (ASIRAS), in IGARSS '02, vol. 6, pp. 3099-3101, Inst. of Electr. and Electr. Eng., New York.

Looyenga, H. (1965), Dielectric constants of heterogeneous mixtures, Physica, 31, 401-406.

McConnell, J. R., G. Lamorey, E. Hanna, E. Moseley-Thompson, R. C. Bales, D. Bele-Oudry, and J. D. Kyne (2001), Annual net snow accumulation over southern Greenland from 1975 to 1998, J. Geophys. Res., 106, $33,827-33,837$ 
Morris, E. M., and J. D. Cooper (2003), Density measurements in ice boreholes using neutron scattering, J. Glaciol., 49, 599-604.

Raney, R. K. (1998), The delay/Doppler radar altimeter, IEEE Trans. Geosci. Remote Sens., 36, 1578-1588.

Raney, R. K., and C. J. Leuschen (2004), Simultaneous laser and radar altimeter measurements over land and sea ice, in IGARSS '04, vol. 1, Inst. of Electr. and Electr. Eng., New York.

Vaughan, D. G., P. S. Anderson, J. C. King, G. W. Mann, S. D. Mobbs, and R. S. Ladkin (2004), Imaging of firn isochrones across an Antarctic ice rise and implications for patterns of snow accumulation rate, J. Glaciol., 50, 413-418.

Wingham, D. J., L. Phalippou, C. Mavrocordatos, and D. Wallis (2004), The mean echo and echo cross product from a beamforming interferometric altimeter and their application to elevation measurement, IEEE Trans. Geosci. Remote Sens., 42, 2305-2323.
Wingham, D. J., et al. (2006), CryoSat: A mission to determine the fluctuations in Earth's land and marine ice fields, Adv. Space Res., in press.

R. Cullen, ESTEC, European Space Agency, NL-2200 Noordwijk, Netherlands.

R. L. Hawley, E. M. Morris, and A. P. Shepherd, Scott Polar Research Institute, University of Cambridge, Cambridge CB2 1ER, UK. (robert. hawley@spri.cam.ac.uk)

U. Nixdorf, Alfred Wegener Institute for Polar and Marine Research, D-27568 Bremerhaven, Germany.

D. J. Wingham, Centre for Polar Observation and Modelling, University College London, London WC1E 6BT, UK. 